\title{
Paediatric procedural sedation at a tertiary care university teaching hospital in India
}

\author{
*Anagha Dubhashi ${ }^{1}$, Maria Silveira ${ }^{1}$, Kiran Hebbar ${ }^{2}$, Courtney McCracken ${ }^{3}$, Ashwin Sardesai $^{1}$, Pradip \\ Kamat $^{2}$
}

Sri Lanka Journal of Child Health, 2018; 47(1): 8-15

\begin{abstract}
Introduction: Although paediatric procedural sedation (PPS) using propofol is routine in the United States, its use is restricted to anaesthesiologists in many other countries like India. As a result the paediatric providers have to use other drugs for PPS.
\end{abstract}

Objective: To report a single centre experience of children receiving PPS at a tertiary care university teaching hospital.

Method: A retrospective chart review of PPS at Goa Medical College, Goa, India was provided by the paediatric senior resident, supervised by a paediatric consultant, both certified in Paediatric Advanced Life Support (PALS) and with experience in nonpropofol PPS. We collected demographics, drug and dosing information, indication for PPS, procedure success rates and adverse events. Sedation related minor adverse events are complications during PPS, which are easily handled, and not expected to be associated with any sequelae. Serious adverse events include aspiration, airway obstruction, laryngospasm, emergent anaesthesia consult, cardiac arrest and death.

Results: Procedural sedation from 249 children from April-September 2015 were included in this study. Magnetic resonance imaging (MRI) 138/249 (55.4\%), computed tomography (CT) scan 61 (24.5\%), electroencephalogram (EEG) 26 (10.4\%) and other procedures $24(9.6 \%)$. Median age was 22 months (25th-75th: 12-36), 140 (56.2\%) were female, and 227 (91.5\%) were American Society of Anaesthesiologists Physical Status (ASA-PS) $\leq$ III.

\begin{tabular}{l}
\hline${ }^{1}$ Goa Medical College, India, ${ }^{2}$ Children's \\
Healthcare of Atlanta at Egleston, Emory University \\
School of Medicine Atlanta, USA, ${ }^{3}$ Emory \\
University School of Medicine, Atlanta, USA \\
${ }^{*}$ Correspondence: anaghasambari@rediffmail.com
\end{tabular}

(Received on 23 March 2017: Accepted after revision on 19 May 2017)

The authors declare that there are no conflicts of interest

Personal funding was used for the project.

Open Access Article published under the Creative

Commons Attribution CC-BY cc) (†) License
Overall success was $213(85.5 \%)$. Commonly used agents included intravenous (IV) midazolam 188 (75.5\%), IV dexmedetomidine 37 (14.9\%), and oral chloral hydrate 24 (9.6\%). Ramsey sedation score of 3 or greater was achieved in $220(88.4 \%)$ sedation after adding a second drug. Serious adverse events were seen in $3(1.2 \%)$ patients. Sedation related minor adverse effects included: change in heart rate $(>25 \%$ from baseline) $47 \quad(18.9 \%)$, oxygen desaturation ( $<90 \%$ for 30 seconds) $32(12.9 \%)$, and agitation/delirium 52 (20.9\%). Only 21 (8.4\%) required oxygen.

Conclusion: Intravenous midazolam was the commonest agent used for procedural sedation at Goa Medical College, India.

DOI: http://dx.doi.org/10.4038/sljch.v47i1.8423

(Key words: Procedural sedation, midazolam, propofol, adverse events)

\section{Introduction}

Paediatric procedural sedation (PPS) is required for radiologic imaging as well as other diagnostic and therapeutic procedures. The aim of PPS is to provide sedation, analgesia, amnesia and immobility if required for the successful completion of the procedure. In the United States (US) a significant number of children receive PPS outside the operating room provided by various paediatric subspecialists such as from paediatric critical care, paediatric emergency medicine, and paediatric hospitalists ${ }^{1}$. Propofol, because of its pharmacological properties like quick onset and short duration of action, is the preferred sedation agent either alone or in combination with fentanyl or ketamine, allowing for rapid turnover of patients and optimal sedation ${ }^{2,3}$. PPS performed by paediatric subspecialists outside the operating room in the US has been shown to be highly effective, resulting in cost saving and improved parental satisfaction ${ }^{4-6}$. There is limited data about PPS from India ${ }^{7-8}$. Published surveys suggest significant variation in the sedation provider, the location of procedure (operating room vs. outside the operating room) and medications used $^{9,10}$.

\section{Objective}

To evaluate the PPS practice at a major tertiary care university teaching hospital in India. 
Method

The sedation provider

Sedations were performed by a senior paediatric resident, under the supervision of an attending consultant paediatrician with experience in procedural sedation. Additionally, the consultant physician attended the paediatric BASIC course, a 2-day course, covering the essential and fundamental aspects of paediatric intensive care, a project of the World Federation of Paediatric Intensive and Critical Care Societies. Paediatric
Advanced Life Support (PALS) was mandatory for all sedation providers. The physician team was accountable for pre-sedation assessment, physical examination, consent, administering sedation medications, monitoring patient's vital signs, airway management, and overseeing the sedation and recovery process. NPO (nil per os or nothing by mouth) guidelines recommended by the American Academy of Paediatrics (AAP) for PPS were followed ${ }^{11}$.

Nil per os (NPO) guidelines recommended by the American Academy of Paediatrics (AAP) for PPS

\begin{tabular}{|l|c|}
\hline Clear liquids* & 2 hours \\
\hline Breast milk & 4 hours \\
\hline Infant formula & 6 hours \\
\hline Solid food (light meal or meals rich in fat, protein or fried foods) & \multicolumn{1}{c|}{$6-8$ hours } \\
\hline
\end{tabular}

* includes water, juice with no pulp, carbonated beverages, tea and black coffee

${ }^{\wedge}$ Meals that include fried or fatty foods or meat (which prolong gastric emptying) may require 8 hours of NPO time.

\section{Location, equipment, and patient monitoring}

Non-radiology procedures were performed in the treatment room on the paediatric in-patient floor. The senior paediatric resident was responsible for carrying the resuscitation equipment and sedation medications to the site of procedural sedation. Resuscitation equipment included an appropriate size bag and mask, laryngoscopes, endotracheal tubes, suction apparatus, and a reversal agent flumazenil. Monitoring included continuous pulseoximetry, non-invasive blood pressure, and heart rate. No end-tidal monitoring was used.

\section{Pre-sedation assessment}

A pre-sedation evaluation was performed by the sedation provider to carefully screen patients who could be at higher risk of having airway complications. Patients with genetic syndromes, prematurity (postconceptional age $<60$ weeks), upper respiratory tract infection, asthma, cardiac disease, cerebral palsy, obesity (body mass index $>30 \mathrm{~kg} / \mathrm{m}^{2}$ ), gastro-oesophageal reflux disease and obstructive sleep apnoea, American Society of Anaesthesiologists Physical Status (ASA-PS) classification $\geq$ IV were carefully screened and if deemed not to be candidates for sedation then cancelled or referred to an anaesthesiologist.

American Society of Anaesthesiologists Physical Status (ASA-PS) classification

\begin{tabular}{|c|l|}
\hline Class & \multicolumn{1}{|c|}{ Description } \\
\hline I & Normal healthy patient \\
\hline II & A patient with mild systemic disease \\
\hline III & A patient with severe systemic disease \\
\hline IV & A patient with severe systemic disease that is a constant threat to life \\
\hline V & Moribund patient who is not expected to survive without surgery \\
\hline
\end{tabular}

\section{Sedation medication}

Chloral hydrate $(50-100 \mathrm{mg} / \mathrm{kg} / \mathrm{dose})$ was the only oral medication used. If the patient was not adequately sedated with chloral hydrate despite a supplemental dose of $25 \mathrm{mg} / \mathrm{kg} /$ dose, a dose of midazolam $(0.1 \mathrm{mg} / \mathrm{kg} /$ dose $)$ was used intravenously (IV) as an adjunct. Midazolam $(0.1-0.6 \mathrm{mg} / \mathrm{kg} / \mathrm{dose})$ or dexmedetomidine $(1-2 \mathrm{mcg} / \mathrm{kg} / \mathrm{dose}) \mathrm{IV}$ were used as primary agents. If the patient was not adequately sedated with either midazolam or dexmedetomidine, then ketamine IV $1 \mathrm{mg} / \mathrm{kg}$ was used as an adjunct to complete the procedure. Due to institutional regulations, propofol was not allowed to be used for PPS by the sedation providers. Furthermore, the use of opioids outside the paediatric intensive care unit was not allowed. Ketamine was mainly used in combination with midazolam for procedures such as kidney and bone marrow biopsies. The depth of sedation was monitored using the Ramsey sedation scale ${ }^{12}$.

\section{Outcome measures}

We assessed the incidence of adverse events (AE) and serious adverse events (SAE) as outcome measures. SAE were defined as any one of the following: (1) Airway obstruction, (2) laryngospasm (complete or near-complete lack of air movement with respiratory effort and/or stridor) $)^{1,5}$, (3) emergent airway intervention (intubation, positive pressure ventilation, or placement of another airway 
device such as an oral airway or laryngeal mask airway), (4) unplanned hospital admission, (5) aspiration, (6) cardiac arrest, (7) death. Sedationrelated minor adverse events included the following: (1) Agitation, (2) brief apnoea (cessation of respiration for $>15$ seconds), (3) desaturation (oxygen saturation on pulse oximetry $<90$ for $>30$ s), (4) hypotension, (5) stridor.

\section{Discharge criteria}

Patients were discharged when they met standard age appropriate procedural sedation discharge criteria which include, ability to take oral liquids, a return of baseline mental status and vital signs stability is achieved ${ }^{11}$. Sedation duration was defined as the time of drug administration till the return to baseline mental status and vital signs were stable.

\section{Statistics and data collection}

This is a retrospective study of all PPS performed at Goa Medical College, Goa, India from AprilSeptember 2015. The study was approved by the institutional ethics committee. Descriptive statistics were calculated using counts and frequencies, medians and ranges, or means and confidence intervals (CI) for patient demographics and sedation procedure characteristics, risk factors and AEs. Rates of events were calculated, and 95\% CIs for these rates were provided. Chi-square tests and Wilcoxon-rank sum tests were used to compare characteristics of patients experiencing a sedation event to those that did not. Statistical significance was assessed using a significance level of 0.05 unless otherwise noted, and two-sided statistical tests are reported.

\section{Results}

Patient demographics are shown in Table 1.

A total of 249 patients who underwent PPS were included in this study. The most common indication for PPS was neurological in $201(81 \%)$ followed by oncology/ gastrointestinal in $13(5 \%)$ of the cases respectively. PPS was performed on $150(60 \%)$ outpatients who were given appointments on selected days whereas 99 (40\%) of the patients were inpatients who needed PPS for certain diagnostic procedures. Types of procedure for which PPS was provided are shown in Figure 1. Sedation medications (primary and secondary drugs) used are shown in Table 2.

Table 1: Patient demographics $(n=249)$

\begin{tabular}{|l|c|}
\hline \multicolumn{1}{|c|}{ Characteristic } & Result \\
\hline Age $($ months $)$, median $\left(25^{\text {th }}-75^{\text {th }}\right)$ & $22(12-36)$ \\
\hline Weight $(\mathrm{kg})$, median $\left(25^{\text {th }}-75^{\text {th }}\right)$ & $10(08-12)$ \\
\hline Sex-Female, No. $(\%)$ & $140(56.2)$ \\
\hline ASA-PS Score, No. $(\%)$ & $21(08.5)$ \\
I & $206(83.1)$ \\
II & $21(08.5)$ \\
III & \\
\hline Admission Status, No. (\%) & $99(39.8)$ \\
Inpatient & $150(60.2)$ \\
Outpatient & \\
\hline Nil per os (NPO) status & $248(99.6)$ \\
NPO for clears $\geq 2$ hrs. No. (\%) & $105(42.5)$ \\
NPO status for solids $\geq 6$ hrs. No. & \\
(\%) (n = 247) & \\
\hline Procedure Type, No. (\%) & $61(24.5)$ \\
Computed Tomography (CT) scan & $105(42.5)$ \\
Magnetic resonance imaging (MRI) & $50(20.1)$ \\
\hline
\end{tabular}

ASA-PS: American Society of Anaesthesiologists Physical Status

Table 2: Sedation medication used for PPS

\begin{tabular}{|l|c|}
\hline \multicolumn{1}{|c|}{ Sedation medication used } & No. (\%) \\
\hline Primary medication & $188(75.5)$ \\
Midazolam & $37(14.9)$ \\
Dexmedetomidine & $24(09.6)$ \\
Chloral Hydrate & $113(45.4)$ \\
Adjunctive medication & $56(22.5)$ \\
Midazolam $\rightarrow$ Dexmedetomidine & $38(15.3)$ \\
Midazolam $\rightarrow$ Ketamine & $15(06.0)$ \\
Chloral hydrate $\rightarrow$ Midazolam & $03(01.2)$ \\
Dexmedetomidine $\rightarrow$ Midazolam & $01(0.4)$ \\
Dexmedetomidine $\rightarrow$ Ketamine & 0 \\
\hline Drug infusion & \\
\hline
\end{tabular}




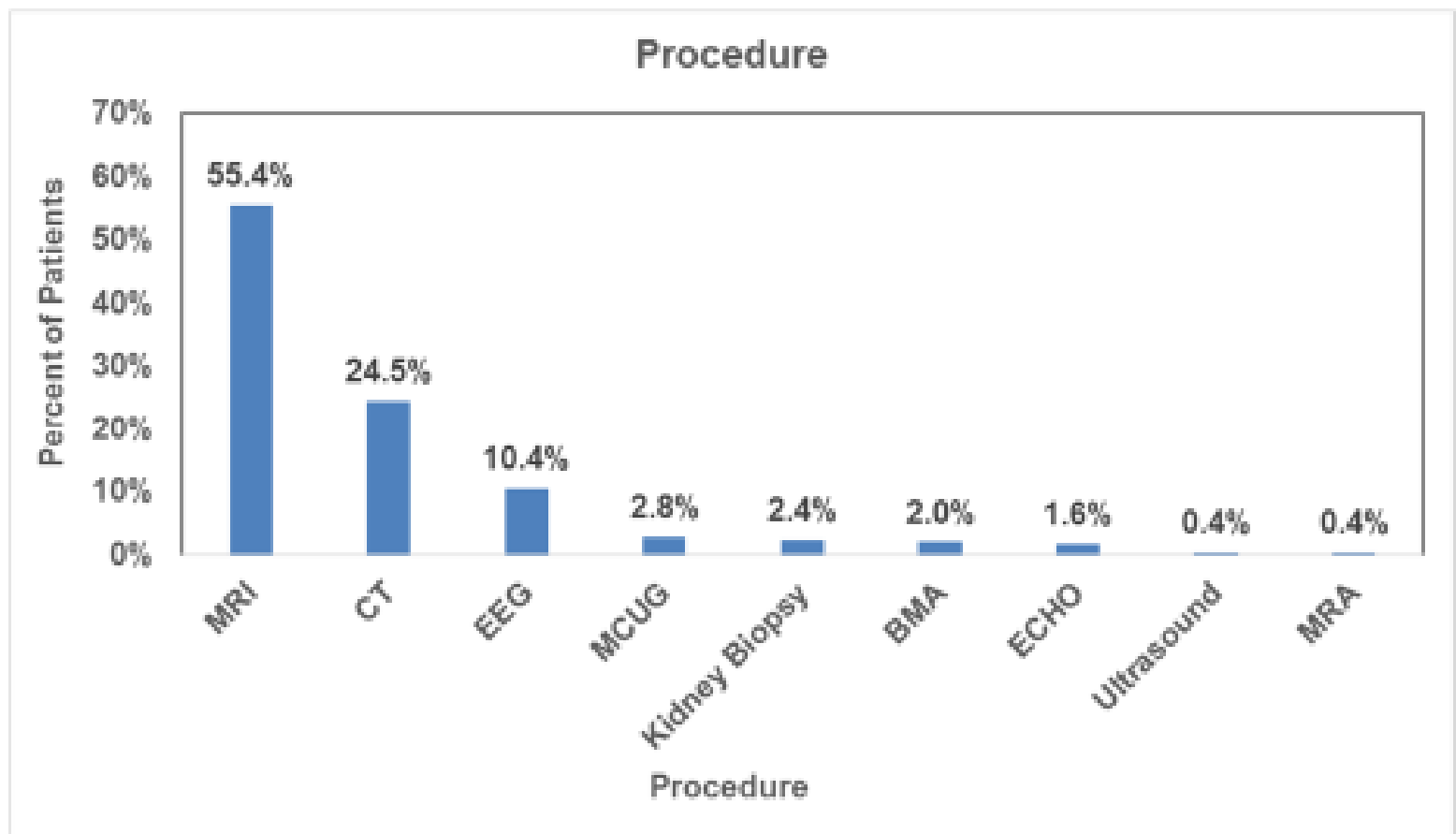

Figure 1: Types of procedure for which PPS was provided

$C T=$ computed tomography, EEG= electroencephalogram, ECHO = echocardiography, $M C U G=$ micturating cystourethrogram, MRI = Magnetic resonance imaging, BMA = bone marrow aspiration, $M R A=$ magnetic resonance angiography

Midazolam and dexmedetomidine (DEX) given IV were the most commonly used primary agents. Chloral hydrate was used by the oral route and not rectally. Secondary drug (adjunct) was used in case of inadequate Ramsey sedation score despite using a supplemental dose of the primary drug. A secondary drug was required in $113(45.4 \%)$ of the patients after administration of the primary drug. Adverse events/interventions and procedure success rates are shown in Table 3.

Table 3: Adverse events/interventions and procedure success rates $(n=249)$

\begin{tabular}{|l|c|}
\multicolumn{2}{|c|}{ procedure success rates $(\boldsymbol{n}=\mathbf{2 4 9})$} \\
\hline \multicolumn{1}{|c|}{ No. (\%) } \\
\hline Study completed & $213(85.5)$ \\
\hline Serious adverse events (SAE) & $\mathbf{0 3}(\mathbf{0 1 . 2 )}$ \\
Upper airway obstruction & $02(0.8)$ \\
Transfer to PICU & $03(01.2)$ \\
Emergency anaesthesia & $02(0.8)$ \\
Consult & \\
\hline Minor adverse events & $\mathbf{9 4}(\mathbf{3 7 . 8 )}$ \\
Desaturation & $32(12.9)$ \\
Coughing & $18(07.2)$ \\
Change in heart rate $>30 \%$ & $47(18.9)$ \\
Hypotension & $11(04.4)$ \\
Agitation/ Delirium & $52(20.9)$ \\
\hline Required Intervention & $\mathbf{2 4}(\mathbf{9 . 6 \%})$ \\
Oxygen & $21(08.4)$ \\
Suctioning & $03(01.2)$ \\
Fluid Bolus & $02(0.8)$ \\
Atropine & $03(01.2)$ \\
\hline Parent Satisfaction & $\mathbf{2 1 3 ( 8 5 . 5 )}$ \\
\hline Radiology Satisfaction & $\mathbf{2 1 3 ( 8 5 . 5 )}$ \\
\hline
\end{tabular}

No patient had cardiac arrest, death, or aspiration. Airway obstruction was seen in two patients. The clinical profile of patients who developed severe upper airway obstruction was as follows: patients were infants aged six months and nine months respectively of ASA-PS Class II with the former infant being premature. Both received midazolam and ketamine combination for sedation. Both patients were rescued using jaw thrust, oxygen via bag-mask and required monitoring in the paediatric intensive care unit (PICU) prior to discharge. A 36 month old female with cerebral palsy and a history of cardiac disease (ASA PS Class II) who received midazolam with adjunctive ketamine for an MRI of the brain and spine had to be admitted to PICU because patient experienced desaturation, hypotension, agitation and excessive secretions. Patient required suctioning, fluid bolus and atropine.

Sedation-related minor adverse events (AE) were seen in $94(37.8 \%)$ patients undergoing PPS. A change in heart rate $>30 \%$ from the baseline was seen with DEX but did not require any intervention. Hypotension was a minor adverse event noted in $4.4 \%$ of the cases. Only two patients required a fluid bolus of normal saline. No respiratory depression was noted following midazolam administration used as a sole agent or along with a secondary IV agent. Agitation/delirium was seen in 52 (20.9)\% of the cases more following chloral hydrate administration along with a concurrent use of a secondary agent like midazolam. Flumazenil was not used in any patients 
as the agitation/delirium was of short duration and self-resolved

Procedure success (completion of the procedure using PPS) was seen in $213(85.5 \%)$ patients. Of the 36 patients who did not complete the study, 34 had an inadequate Ramsey sedation score and 2 patients developed severe upper airway obstruction and could not successfully complete the procedure. Overall parental satisfaction with PPS was $85.5 \%$.
Risk factor analysis for adverse events are provided in table 4. Comparisons among patients that experienced an AE to those that did not showed that younger age $(\mathrm{p}=0.025)$, higher ASA-PS classification $(p=0.015)$, the presence of cerebral palsy $(p=0.040)$, the use of dexmedetomidine $(p=0.013)$ and need for a secondary agent were associated with an adverse event.

Table 4: Risk factors associated with sedation related complication or serious adverse event

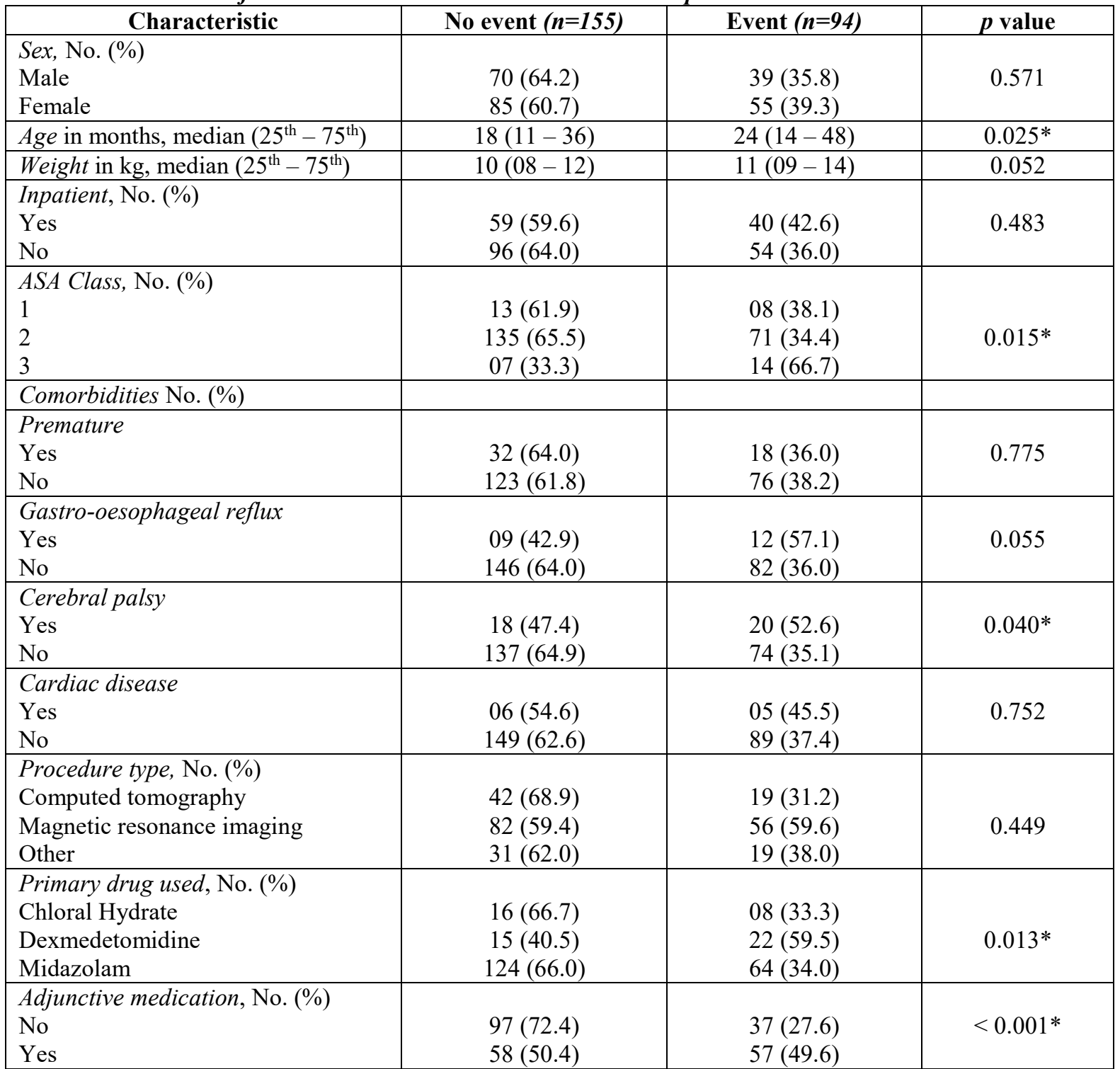

\section{Discussion}

The goals of PPS as outlined by the AAP include patient safety, minimization of pain and discomfort, anxiolysis, amnesia, immobility and return of patient to a baseline level which is safe for discharge ${ }^{11}$. Furthermore, Cote et al have stressed on the use of the fewest number of drugs and the lowest dose possible to match the type of procedure ${ }^{11,13}$. This study focuses on the sedation provided by general paediatricians at a tertiary care university teaching hospital in India. Several barriers to PPS in resource limited countries like India result in wide practice variation, violation of AAP paediatric sedation guidelines resulting in a lower success rate of PPS $^{9,10}$. The restriction of drugs (by institutional or anaesthesia policy) which provide analgesia such as opioids, or deep sedation such as propofol, can result in inability to provide adequate pain control or immobilization required for non-radiology procedures. The restriction of drugs also necessitates 
the use of more than one agent which can result in an increased incidence of $\mathrm{AE}^{13}$. Additionally the shortage of anaesthesiologists, operating room availability, a dedicated sedation service comprised of paediatric subspecialists, places the burden of providing PPS on the general pediatricians, as in this study.

Our study shows that the general paediatricians provide PPS for children in the age range of 12-36 months, usually ASA-PS I or II for a variety of procedures, majority of which involves radiologic imaging. Similar findings were reported by Monroe et al when they analysed procedural sedations provided by paediatricians in the US from a large sedation database (PSRC) that paediatricians sedate younger patients, mostly ASA-PS I or II, nonpainful, non-emergency procedures such as radiologic imaging when compared to PPS provided by paediatric subspecialists ${ }^{14}$. The overall procedure success rate was about $85 \%$ which can be attributed to the medications used for PPS in this study. The primary agent used in $76 \%$ of patients in this study was IV midazolam. Intravenous DEX was the second most commonly used agent. IV midazolam was also used if patients were inadequately sedated by chloral hydrate, another commonly used agent besides the above two agents. The liquid formulation of chloral hydrate is no longer available in the US and the use of this agent is on the decline ${ }^{11}$. Ketamine was used as a secondary agent in $15 \%$ of the patients if inadequately sedated by midazolam. Interestingly no opioids, barbiturates or any sedative infusions were utilized in this study. The use of a single bolus rather than an infusion of the sedative could also explain the lower success rate compared to studies that utilize propofol or ketamine which report much higher procedure success rates ${ }^{15,16}$. It is possible that due to the fear attributed to ketamine's side effect profile especially laryngospasm, the paediatricians were reluctant to use that as a first line agent for non-radiology procedures ${ }^{17,18}$. The overall parental or radiology satisfaction was also low. This can be probably attributed to the higher failure rate due to inadequate sedation or AE. Parents have to take off work or travel long distances to bring the child to the hospital.

The overall incidence of sedation related minor AE was much higher $(37 \%)$ compared to studies in which PPS was provided by paediatric subspecialists. Serious AE rate was however low $(1.2 \%)$ compared to other studies and could be attributed to the type of medications used in our study (i.e. no propofol $)^{15}$. None of the patients had aspiration, required cardiopulmonary resuscitation or died.

When we examined risk factors for $\mathrm{AE}$, we found that younger age, higher ASA-PS, use of multiple drugs was associated with increased incidence of AE. These findings are similar to what has been published previously $y^{5,11,15}$. Additionally patients with a diagnosis of cerebral palsy were at a higher risk of $\mathrm{AE}$ and this is consistent with findings from other studies especially with use of midazolam which has been to shown to give rise to agitation and delayed recovery ${ }^{19}$. This higher incidence of AE in patients with cerebral palsy could be attributed to multiple factors such as muscle tone, pharyngeal collapse, increased secretions and drug interactions with various medications used daily such as baclofen $^{20}$. We excluded all patients with a recent active upper respiratory infection as sedation candidates as there are some publications which have elucidated to the higher risk of adverse events and sedation failure in these patients ${ }^{21]}$ The risk for $\mathrm{AE}$ in our patients with prematurity, gastrooesophageal reflux disease and cardiac disease was not statistically significant, although studies have shown that these patients are at higher risk for $\mathrm{AE}$ with sedation ${ }^{15,22,23,24}$.

This study has several limitations. The results of this observational study are from a single centre with a small sample size. Because there is no control group, we are unable to draw a direct cause and effect from our study. Additionally, the drug regimen used was not uniform in all patients, therefore, the $\mathrm{AE}$ reported may have varied on that account. We did not follow-up on patients once they were discharged from the hospital. Adverse reactions could have occurred at home and we would not have been aware of them. Finally, we did not take into account AE in relation to the level of sedation. There is a possibility that rate of AEs increase as the depth of sedation increases. There is no pre-screening of high risk patients prior to their appointment and patient are frequently cancelled on the day of their arrival. Distraction techniques to accomplish procedures were not utilized in our study due to resource limitation. End-tidal monitoring was also was not available for PPS provided in this study.

\section{Conclusions}

Midazolam IV was the commonest agent used for procedural sedation at Goa Medical College, India.

\section{References}

1. Couloures KG, Beach M, Cravero JP, Monroe KK, Hertzog JH. Impact of provider specialty on paediatric procedural sedation complication rates. Pediatrics 2011; 127(5):e1154-60.

https://doi.org/10.1542/peds.2010-2960

PMid: 21518718

2. Berkenbosch JW. Options and considerations for procedural sedation in 
paediatric imaging. Paediatric Drugs 2015: 17 (5):385-99. https://doi.org/10.1007/s40272-015-01406

PMid: 26156106

3. Chidambaran V, Costandi A, D'Mello A. Propofol: a review of its role in paediatric anaesthesia and sedation. CNS Drugs 2015: 29 (7):543-63.

https://doi.org/10.1007/s40263-015-02596

PMid: 26290263 PMCid: PMC4554966

4. Lalwani K, Michel M. Paediatric sedation in North American children's hospitals: a survey of anaesthesia providers. Paediatric Anaesthesia 2005; 15(3):209-13.

https://doi.org/10.1111/j.14609592.2005.0

1437.x

PMid: 15725318

5. Cravero JP, Beach ML, Blike GT, Gallagher SM, Hertzog JH, Paediatric Sedation Research C. The incidence and nature of adverse events during paediatric sedation/anaesthesia with propofol for procedures outside the operating room: a report from the Paediatric Sedation Research Consortium. Anesthesia and Analgesia 2009; 108(3):795-804.

https://doi.org/10.1213/ane.0b013e31818f c334

PMid: 19224786

6. Uri O, Behrbalk E, Haim A, Kaufman E, Halpern P. Procedural sedation with propofol for painful orthopaedic manipulation in the emergency department expedites patient management compared with a midazolam/ketamine regimen: a randomized prospective study. Journal of Bone and Joint Surgery American Volume 2011; 93(24):2255-62.

https://doi.org/10.2106/JBJS.J.01307

PMid: 22258771

7. Chandar R, Jagadisan B, Vasudevan A. Propofol-ketamine and propofol-fentanyl combinations for non-anaesthetistadministered sedation. Journal of Pediatric Gastroenterology and Nutrition 2015; 60(6):762-8.

https://doi.org/10.1097/MPG.0000000000 000722

PMid: 25996793

8. Borker A, Ambulkar I, Gopal R, Advani $\mathrm{SH}$. Safe and efficacious use of procedural sedation and analgesia by nonanesthesiologists in a paediatric haematology-oncology unit. Indian Pediatrics 2006; 43(4):309-14.

PMid: 16651669

9. Arora RS, Kulkarni KP, Alston RD. A survey of procedural sedation and analgesia practices in paediatric oncology centres in India. Indian Journal of Pediatrics 2012; 79(12):1610-6. https://doi.org/10.1007/s12098-012-0724$\mathrm{X}$

PMid: 22421934

10. Jagadisan B. A survey of procedural sedation for paediatric gastrointestinal endoscopy in India. Indian Journal of Gastroenterology 2015; 34(2):158-63. https://doi.org/10.1007/s12664-015-05565

PMid: 25917522

11. Cote CJ, Wilson S, American Academy of Pediatrics, American Academy of Pediatric Dentistry. Guidelines for monitoring and management of paediatric patients before, during, and after sedation for diagnostic and therapeutic procedures: Update 2016. Pediatrics 2016; 138(1):pii

12. Ramsay MA, Savege TM, Simpson BR, Goodwin R. Controlled sedation with alphaxalone-alphadolone. British Medical Journal 1974; 2(5920):656-9. https://doi.org/10.1136/bmj.2.5920.656 PMid: 4835444 PMCid: PMC1613102

13. Cote CJ, Karl HW, Notterman DA, Weinberg JA, McCloskey C. Adverse sedation events in paediatrics: analysis of medications used for sedation. Pediatrics 2000; 106(4):633-44.

https://doi.org/10.1542/peds.106.4.633

PMid: 11015502

14. Monroe KK, Beach M, Reindel R, Badwan L, Couloures KG, Hertzog JH, et al. Analysis of procedural sedation provided by paediatricians. Pediatrics international 2013; 55(1):17-23.

https://doi.org/10.1111/j.1442200X.2012. 03743.x

PMid: 23062205

15. Mallory MD, Baxter AL, Yanosky DJ, Cravero JP, Pediatric Sedation Research Council. Emergency physicianadministered propofol sedation: a report on 
25,433 sedations from the paediatric sedation research consortium. Annals of Emergency Medicine 2011; 57(5):462-8 e1.

16. Sulton C, McCracken C, Simon HK, Hebbar K, Reynolds J, Cravero J, et al. Paediatric procedural sedation using dexmedetomidine: A report from the Paediatric Sedation Research Consortium. Hospital Pediatrics. 2016 Aug 11. https://doi.org/10.1542/hpeds.2015-0280 PMid: 27516413

17. Green SM, Roback MG, Kennedy RM, Krauss B. Clinical practice guideline for emergency department ketamine dissociative sedation: 2011 update. Annals of Emergency Medicine 2011; 57(5):44961.

https://doi.org/10.1016/j.annemergmed.20 10.11.030

PMid: 21256625

18. Grunwell JR, Travers C, McCracken CE, Scherrer PD, Stormorken AG, Chumpitazi $\mathrm{CE}$, et al. Procedural Sedation Outside of the Operating Room Using Ketamine in 22,645 Children: A Report From the Paediatric Sedation Research Consortium. Paediatric critical care medicine: a journal of the Society of Critical Care Medicine and the World Federation of Paediatric Intensive and Critical Care Societies. 2016 Aug 8.

19. Yoshikawa F, Tamaki Y, Okumura H, Miwa Z, Ishikawa M, Shimoyama K, et al. Risk factors with intravenous sedation for patients with disabilities. Anesthesia Progress 2013; 60(4):153-61. https://doi.org/10.2344/0003-300660.4.153

PMid: 24423418 PMCid: PMC3891456
20. Frei FJ, Haemmerle MH, Brunner R, Kern C. Minimum alveolar concentration for halothane in children with cerebral palsy and severe mental retardation. Anaesthesia 1997; 52(11):1056-60. https://doi.org/10.1111/j.13652044.1997.2 57-az0376.x

PMid: 9404166

21. Grunwell JR, McCracken C, Fortenberry J, Stockwell J, Kamat P. Risk factors leading to failed procedural sedation in children outside the operating room. Pediatric Emergency Care 2014; 30(6):381-7. https://doi.org/10.1097/PEC.00000000000 00143

PMid: 24849275

22. Havidich JE, Beach M, Dierdorf SF, Onega T, Suresh G, Cravero JP. Preterm versus term children: Analysis of sedation/anesthesia adverse events and longitudinal risk. Pediatrics 2016; 137(3):e20150463 https://doi.org/10.1542/peds.2015-0463 PMid: 26917674

23. Sanborn PA, Michna E, Zurakowski D, Burrows PE, Fontaine PJ, Connor L, et al. Adverse cardiovascular and respiratory events during sedation of pediatric patients for imaging examinations. Radiology 2005; 237(1):288-94. https://doi.org/10.1148/radiol.2371041415 PMid: 16183936

24. Vespasiano M, Finkelstein M, Kurachek S. Propofol sedation: intensivists' experience with 7304 cases in a children's hospital. Pediatrics 2007; 120(6): e1411-7. https://doi.org/10.1542/peds.2007-0145 PMid: 18055659 